\title{
FORMULATION OF A PROCESS FOR THE PLANNING AND MANAGEMENT OF TECHNOLOGY DEVELOPMENT
}

\author{
Matthew C. Largent", Dimitri N. Mavris ${ }^{\dagger}$ \\ Aerospace Systems Design Laboratory \\ School of Aerospace Engineering, Georgia Institute of Technology
}

Atlanta, GA 30332-0150

\begin{abstract}
Due to the importance of technology use in Aerospace systems, the process of technology development is one of the most important parts of fielding a new system. Technology development is the process of creating and managing activities such as experiments, analysis, and prototyping in order to reduce the risk associated with the use of a new technology. While technical risk is addressed by the activities, the project must be planned and managed so as to reduce the cost and schedule risk associated with completing those activities. This study introduces a process that will assist in the planning and management of a technology development project and lead to successful development efforts.
\end{abstract}

\section{INTRODUCTION}

Since its very beginnings, innovation and the application of knowledge have been necessary elements of success in human flight. The Montgolfier brothers took note of the simple concept that heat reduces the density of air, and launched the first recorded hot air balloon flight. The Wright brothers watched birds in flight, and used their observations (as well as diligent testing) to create their early concepts of wing warping for aircraft control. Early aviation pioneers (including the Wright brothers) realized that the power to weight ratio of the new gasoline engines was higher than steam engines, and so they created gas engines to power their aircraft. New engines, wing warping, and many other advances enabled the powered flight of a heavier-thanair vehicle, and without them it could not have happened. ${ }^{1}$ Ideas such as wing fairings, the jet engine, booster rockets, and ablative tiles have in more recent years enabled human beings to travel faster, further, and higher. This concept, the "practical application of

* Graduate Research Assistant, AIAA Student Member

Boeing Professor for Advanced Design, Director ASDL, AIAA Senior Member

Copyright (C) 2001 by Largent and Mavris. Published by the American Institute of Aeronautics and Astronautics, Inc. with permission. knowledge to create the capability to do something entirely new or in an entirely new way," ${ }^{2}$ is called technology.

The use of technology by the Wright brothers did not come without work. These aviation pioneers went through years of testing in order to come up with their Wright Flier I. The Wright brothers developed their technology through performing tests involving analytical equations and a homemade wind tunnel, creating sub-scale model aircraft, and flying full-scale test aircraft as gliders. This rigorous testing, both in the shop and in the air, was important for a successful first flight. The careful and methodical development of technology is as important today as it was then. A recent study of a United States Department of Defense contract for a weapon's development found that there was an $88 \%$ growth in cost and a $62 \%$ growth in time for the contract's completion which was largely due to insufficient development of technology. The study's overall findings show that commercial and military product development programs which utilize mature technologies typically finish on time and under budget, while programs that begin advanced development with less mature technologies did not meet cost, schedule, and sometimes performance requirements. ${ }^{3}$ Another government study, this time of the Joint Strike Fighter, found that beginning Engineering Manufacturing and Development (EMD) with immature technologies will increase "the likelihood of schedule delays, which in turn result in increased program costs." ${ }^{4}$ This problem does not exist only in the realm of military or aerospace use of technology. A study performed on the development of two new products for Xerox Corporation had similar findings. The principle investigators determined that the product using more mature technology finished development in less time and with less incurred cost than the second product, even though it was more technologically complex. ${ }^{5}$ Since the use of technology and proper technology development are important, it is worthwhile to examine one of the primary factors that influence that development process, risk.

Risk can be defined in its most basic form as the exposure to the possibility of some type of loss or gain due to uncertainty. ${ }^{6}$ That definition will be pursued 
further in the following sections of this study, but typically the loss or gain is considered to be in the areas of cost, time, and technical performance. The uncertainty associated with technology development stems from the fact that the technology is a new and unproven item that is not fully understood, "The newer the technology of a job, the greater the uncertainty that it will be completed as planned."7 Over time the uncertainty due to a technology will change as knowledge changes and grows. ${ }^{8}$ Although uncertainty can result in beneficial or detrimental results, its mere existence is detrimental because it does not allow knowledge of the future worth of the technology. Uncertainty outside of prescribed bounds has been described as a loss of quality. ${ }^{9}$ It follows that reduction of that uncertainty would be beneficial, and indeed, "the purpose of a technology-advancement project is to reduce technical uncertainty."10

If risk or uncertainty reduction is the main focus of technology development, then the method of that reduction becomes important. In the National Aeronautics and Space Administration (NASA) Technology Plan the technology maturation or development process is described as, "a process of testing and analysis that progressively reduces the programmatic risk of selecting that technology for an application and increases the readiness of that technology for use in a mission." ${ }^{2}$ This process is a form of risk management. Risk management is a relatively new discipline that is connected to and shares ideas with other disciplines such as Concurrent Engineering, Design of Experiments and Systems Engineering. Risk management is usually an iterative process; as the technology develops, updated uncertainty information can be added and the risk reevaluated. Risk management is also more effective early in the life cycle of a program. For technology development, this means applying formal risk management processes as early as possible.

Risk management can be considered to have 3 phases: identification, assessment, and control. ${ }^{11}$ Risk identification is the process of determining where the significant uncertainties lie in a project. The results from this phase should be a list of specific areas where uncertainty exists due to the technology, and a description of that uncertainty. The next phase, risk assessment, involves taking the many areas of uncertainty and evaluating their effect on the top-level measures that show the success or failure of the project. This should result in an understanding of the overall project risk. Once the overall risk is known the project must be managed in such a way as to control or reduce that risk. The technical risk is controlled by performing experiments and analysis to determine the technical characteristics of the technology. The cost and schedule risks are controlled by the way those activities (experiments, etc.) are managed. This means that risk management must be performed on the technology as well as the technology development project.

Therefore, it is important to properly manage the product (the technology) and process risk in a technology development process in order to reduce cost and schedule overrun and to control technical uncertainty. This need can be filled by a process that will assist in the planning and management of technology development. This process must be able to determine areas of technical uncertainty and plan experiments to reduce that uncertainty. It must also organize those experiments to alleviate cost and schedule uncertainty, show the cost and benefit associated with developing the technologies (to allow tradeoffs if necessary), and manage the development to ensure that requirements are met. This process must be applied from the beginning of a technology development project to allow for the maximum benefit of risk management. The following sections of this study will give background information on the techniques which might apply to this process, and will suggest a candidate process.

\section{BACKGROUND}

Technology development draws from the disciplines of Project Management and Risk Management. Each provides tools and techniques which assist in planning and managing the technology development process. At the Aerospace Systems Design Lab (ASDL) probabilistic design methods have been developed which focus on bringing knowledge forward in the design process, and research has been done in the areas of technology application and tracking. Finally, existing methods of technology analysis and technology development provide information on the work that is currently being performed in these areas of study

\section{Project Management}

Project management is a very broad discipline that covers both technical and non-technical methods for getting the best results out of a project within set goals for schedule and cost. As the discipline is so broad, this overview will focus on methods and tools that are deemed useful for the planning and management of a technology development project.

One tool borrowed for project management from Systems Engineering is the Work Breakdown Structure (WBS). The WBS is a hierarchical diagram, an example of which can be seen in Figure 1. The purpose 
of the WBS is to break down a product or process into sub-components and then continue that breakdown until the sub-components are at a level in which they can be used by project planners. This can be as many as 6 or more levels down. Variations of this concept of breaking an item or activity down into its smallest components have also been called disaggregation, ${ }^{12}$ generation breakdown (GB), ${ }^{11}$ top-down decomposition, and tree diagramming. ${ }^{13}$

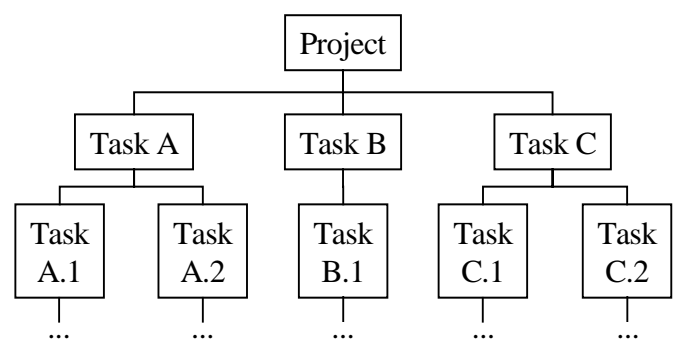

Figure 1: Sample Work Breakdown Structure

The WBS provides one look at how sub-tasks of a project relate to each-other, but there are other ways to relate these low level tasks together. One of the more useful for project planning is the task-precedence or precedence chart. This tool is a precursor to network techniques and its primary purpose is to graphically show the order in which sub-tasks or activities must be completed. Activities are usually represented as nodes, and arrows connect the activities to show the flow of the process. An example can be seen in Figure 2. The precedence chart can also be called a network, and is useful for setting up project network techniques.

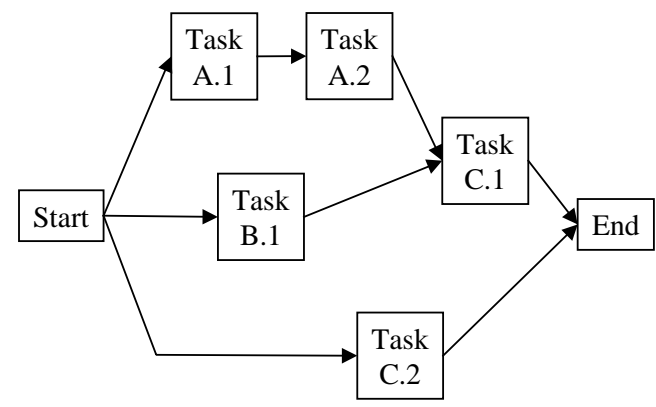

Figure 2: Sample Precedence Chart

Project network techniques were first developed in the mid-'50's to early '60's. Two of the best known of these initial techniques are the Critical Path Method (CPM) and the Program Evaluation and Review
Technique (PERT). Essentially, a project network or network modeling technique is a method of representing the project through use of a diagram using arrows (arcs) and boxes or circles (nodes). In an Activity-on-Arrow (AoA) diagram the arcs represent the activities within the project and the nodes are used to congregate information and simulate decisions. The Activity-on-Node (AoN) method uses the nodes as the activities and the arcs are used to pass information from node to node. The two are very similar and can often be used interchangeably ${ }^{7}$.

Network analysis of the project is performed by assigning costs and times to the individual activities. These values are then combined by the network analysis tool to determine the overall cost and time. The network is created by a number of methods, but the precedence chart listed earlier is one of the best. This chart can be converted into AoA or AoN techniques easily and translated into a fully functioning network with the incorporation of cost and time information for the activities. One problem that can exist is if the network gets too large, as that hinders the ability to visualize the project. A simple way around this is to divide the project up into an overall network with a number of sub-networks, or to divide it into a series of consecutive networks that represent phases of the project. $^{7,14}$ The graphical nature of network management methods is a great help in visualizing the project, and this ease of visualization assists in management and communication. A limitation of the methods is that they best model projects that have a clear beginning and end.

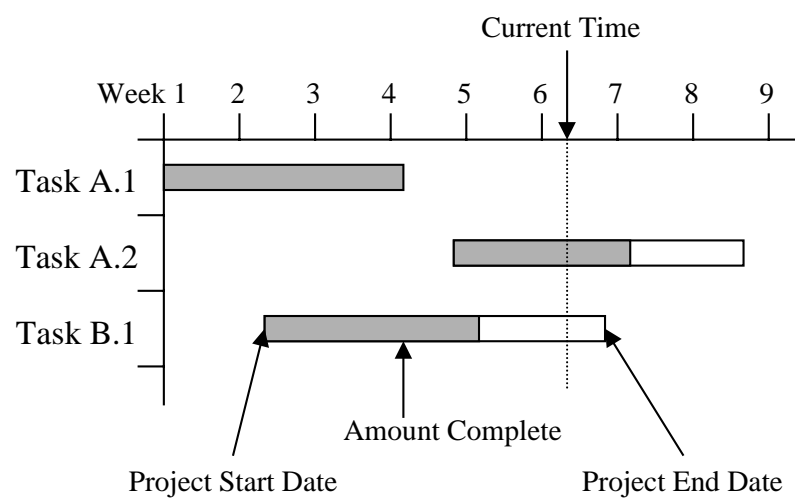

Figure 3: Sample Gantt Chart

Another technique that focuses on visualizing the flow of the project is the Gantt Chart, which was developed as a production control tool in 1917 by Henry L. Gantt. This technique, seen in Figure 3, is a planning method that shows a schedule through 
graphically portraying the projected amount of time necessary for completion, the location along a timeline, and the progress made for a list of activities.

The Gantt chart is an excellent way to visualize the times necessary for specific activities in a project, but before it can be used those times need to be determined. Estimation of time as well as cost is a difficult process, and there are many possible techniques that can be used. See Table 1 for a list of techniques that are helpful in this estimation. For more detail, please see Michaels' work. ${ }^{11}$

\section{Table 1: Cost and Time Estimation Techniques}

\begin{tabular}{|c|c|}
\hline Top-down techniques & Regression equations \\
\hline Bottom-up techniques & Expert opinion \\
\hline Analytical equations & Analogy \\
\hline Parametric equations & Standard Data \\
\hline
\end{tabular}

The project management techniques discussed are applicable for many types of projects including projects focused on risk management. As technology development is in essence a risk management process it is important to examine this field for useful knowledge.

\section{$\underline{\text { Risk Management }}$}

Before defining risk management it is important to have a more detailed definition of risk than that given earlier. To correctly define risk, it is important to first define uncertainty. Uncertainty is the quality of something not being certain to occur, not known beyond doubt, or not clearly identified or defined. Risk can be defined as the following (based on the work of Cooper and Chapman ${ }^{6}$ ) : exposure to the possibility of economic or financial, schedule, or technical performance either above or below target values as a consequence of the uncertainty associated with pursuing a particular course of action. With this definition in mind it is now possible to look at risk management.

Risk management is a specialized subset of project management that deals with risks and uncertainty. Risk management can be seen as a choice between managing a given risk (trying to reduce it) and dealing with the consequences of that risk. The choice between the two is usually made based on cost. Risk management is performed if the expected benefit from avoiding risk is greater than the expected cost associated with that management. Risk management, as mentioned earlier, can be broken up into three phases: identification, assessment, and control. These phases will be used to assist in describing risk management techniques, especially those deemed useful in the development of technology.

\section{Identification}

The identification stage of risk management is focused on determining areas of uncertainty and describing the extent of that uncertainty. The following techniques are used to assist in that process.

The Work Breakdown Structure technique, or some type of top-down decomposition, is often used to assist in the identification of uncertainty. ${ }^{7,11,15,16}$ Breaking a project and/or product down into its component parts allows risks to be specified at a level that is more intuitive. It is the task of the risk assessment phase to aggregate those risks into a overall measure that can be used for decision-making.

The Pareto chart is a useful tool for sorting through the sub-components of a project and attempting to determine the components on which to focus. The Pareto principle is an idea coined by J.M Juran based on his observations and the work of Italian Economist Vilfredo Pareto. ${ }^{17}$ Essentially the Pareto principle, as applied to risk, states that $20 \%$ of the sub-components of a project will account for $80 \%$ of the uncertainty in that project. This means that the focus of risk identification can be on finding that $20 \%$.

Expert opinion is often the ultimate method used for identification and description of uncertainty. Ideally the methods described above help in breaking the project down and identifying areas where uncertainty might exist, but the task of describing that uncertainty is usually left up to an individual or group of individuals. Experts can be anyone who: has extensive knowledge in one of the areas or disciplinary fields associated with the project (from academia, for example), has worked on similar projects in the past, or is experienced in risk analysis. Often teams of people fitting all of these descriptions will be formed to work together on the process of uncertainty identification and description.

The description of uncertainty is simply an accounting for the extent of the uncertainty at the level at which it is identified. This uncertainty is usually defined in the form of a probability distribution. These distributions are difficult to conceptualize, and so techniques have been developed which take simple information provided by an expert and convert that information into a distribution. One of the most common of these methods is the 3-point distribution. Most people can estimate the maximum, minimum, and most likely values of a probabilistic variable. This max, min, and most likely are then used to define a distribution. The simplest way to do this is to use a triangular distribution; the max and the min define the base of the triangle, and the most likely value defines 
the third point. Methods have been derived to create beta distributions, Weibull distributions, and normal distributions from a few discrete values. ${ }^{12,18}$ All of these methods fill the purpose of allowing a probabilistic representation of uncertainty from expert opinion.

The primary case where experts are not used is when there is enough statistical data available to form a distribution from that data. Depending on the type of problem, data might be available for many of the uncertainties given. An example of this type of situation would be if a certain manufacturing process were used which turned out products with varying length. If that process were well known, then the distribution of lengths would be known and could be quantified. This distribution would then be used for risk analysis.

\section{$\underline{\text { Assessment }}$}

Risk assessment (also called analysis or quantification) is defined as, "using the information from risk identification, and one or more quantitative techniques to synthesize the information, to create an overall assessment of program cost, schedule, or technical risk and also an assessment of the risk contributed by each risk area." 18 An exploration of risk assessment involves identifying and examining these quantitative techniques. Cooper and Chapman list the following techniques as being representative of types of assessment: ${ }^{6}$

- Simple Adjustments and Sensitivity Analysis

- Analytical Methods

- Simulation

- Numerical Methods

Of these methods, one of the most widely used is simulation. Simulation is the process of analyzing a model of an object (often a computer model) in order to determine more information about the object. ${ }^{11}$ Monte Carlo simulation is a powerful form of this technique used in risk analysis. It involves defining distributions for inputs of a model, repetitively sampling those distributions, running the model using those samples, and then collecting the results. This process approximates the results as if probabilistic inputs were used and probabilistic outputs returned from the model. Monte Carlo simulation is an easy process to program and can often be performed on discrete-value oriented codes by controlling the inputs, outputs, and running of the code through a short program, often called a script or wrapper.

The network techniques identified earlier can be run as simulations. The initial PERT diagrams attempted to deal with risk by identifying and running best, worst, and most likely cases. Since then techniques have been developed which incorporate probabilistics as a part of their programming. One such technique is the Venture Evaluation and Review Technique, or VERT. VERT was created in the early 1970 's to address perceived shortcomings of some of the other network techniques available at the time. It has since been upgraded, with the current version being supported by the Army Logistics Management College. VERT allows probabilistic network modeling of time, cost, and performance and allows interaction between these areas. An AoA model, VERT has the capability of assigning values to parameters based on 14 standard statistical distributions, histograms (user defined distributions), and mathematical relationships based on previous cost/time/performance values. ${ }^{14}$ This combination of Monte Carlo simulation and networking is a powerful risk assessment tool.

\section{Control}

The last phase of risk management is risk control. This is the point at which action can be taken based on the information gathered and analyzed in the previous two phases. Essentially this is the point at which the risk is managed. As with the other phases there are a number of options that are available to use, some broad examples of which are listed here. ${ }^{16}$ All of these techniques would probably be used to some degree in a typical risk management project.

Uncertainty Reduction: This concept focuses on the knowledge that reduction in the sub-component uncertainties will cause a reduction in the overall uncertainty. Uncertainty reduction techniques focus on the risk in a bottom-up manner. Some techniques used are: creating prototypes, planning experiments, conducting simulations, parallel development efforts, using proven methods and technology, and increasing the training levels of workers.

Consequence Reduction: This is focused on reducing the consequences when risks occur. Two possible techniques are decoupling items, which involves removing their dependencies so risk in one does not affect the other, and providing margins so there is extra money or time to deal with problems that arise.

Risk Avoidance: The idea behind risk avoidance is changing the requirements necessary for portions of the project, or the project as a whole, in order to remove the restrictions that are causing problems.

Risk Transfer: The final method involves transferring the responsibility for the risk to someone else. Insurance is one example of this; if something goes wrong, then the insurer covers the losses. The other example is giving responsibility to lower level project decision-makers for handling risk, therefore encouraging them to deal with risk at their level. 


\section{ASDL Methods}

The Aerospace Systems Design Laboratory (ASDL) is focused on design methodologies for complex systems. Over the years, a number of different methods have been explored and developed in the areas of probabilistic design methodology, technology modeling and application, design for affordability, and robust design simulation. The following methods will provide techniques or ideas that are applicable towards the development of a process for the planning and management of a technology development project.

Response Surface Methodology: ${ }^{19,20}$

The Response Surface Methodology (RSM) is based on the concept that metamodels can be used to represent complex physics-based analysis tools in the conceptual design process, allowing for speed of execution with acceptable levels of error. The primary metamodel used in RSM is the Response Surface Equation (RSE). RSEs are quadratic equations that are regressed from data, usually provided by a Design of Experiments (DOE). The Design of Experiments is a technique used to gather data on a process in the most efficient manner, through a small number of experimental runs. The metamodels created are ideal for use in Monte Carlo simulation because they run quickly and many samples can be taken of the input distributions.

\section{Technology Identification, Evaluation, and Selection: ${ }^{21}$}

The Technology Identification, Evaluation, and Selection process (TIES) was developed at ASDL by Kirby and others to address the question, "Should technologies should be used for this system, and if so, what technologies?" TIES has 8 steps and starts off with defining the problem and the concept space. It models the system, and identifies which requirements are not being met. It then models technologies suggested for use on the system using metrics and technology k-factors. Metrics are simply measures of effectiveness. A top level metric might be weight, while a lower level metric would be material thickness for a sub-component. Technologies are modeled using $\mathrm{k}$-factors by representing the technology in an analysis code by its effect on the metrics. The k-factors represent the benefit or degradation that the technology would have on each metric. Finally, TIES determines which technology or combination of technologies allow the system to meet its requirements, or which come closest to doing so.

\section{Technology Impact Forecasting: ${ }^{22}$}

This method (TIF) is based on the same idea of technology modeling as TIES, but works from the topdown instead of the bottom-up. Whereas TIES takes a list of technologies and determines which would be best for a given system, TIF focuses on identifying areas where technologies will be needed. In this approach an RSE or some other metamodel is used to model the toplevel performance/cost/etc. of the system in question. This metamodel is used to identify the requirements that are not being met and the metrics that have the greatest effect towards meeting those requirements. Once these key metrics are identified it is possible to determine the amount of change in the metrics that is necessary to meet the requirements. These metrics, and the modification needed to them, help to identify areas where technologies could be used for improvement.

Technology Metric Assessment and Tracking: ${ }^{23}$

The Technology Metric and Tracking (TMAT) process is one of the newest of ASDL's methods, and is focused on tracking the progress of technologies in the development process. TMAT is based on concepts from TIES as well as the technology tracking work done by Ward ${ }^{24}$ and others for the NASA High Speed Research program. The TMAT process contains 5 steps: metrics identification, technology audit, metrics assessment, metrics integration, and metrics sensitivity analysis. Metrics identification simply identifies the proper metrics to use in tracking a technology. Technology Audit gathers information on the technology's progress while metrics assessment is where that data is converted into a form suitable for analysis. Metrics integration involves the creation of an analytical environment where the technology data can be analyzed to show its effect on the overall development project goals. Finally, in the sensitivity analysis phase the actual analysis is performed and the progress-to-date and the progress needed for the technology are shown. The process is iterative from the second step on, allowing the technology's progress to be tracked yearly.

\section{Technology Analysis and Development:}

The analysis and development of technologies has been occurring for many years, and so it makes sense to examine past work in those areas for useful tools and techniques. Beyond the technology development process itself two items of interest are the measurement of technology development and tracking the technology development process. With many commercial entities these processes and techniques are proprietary, because technology development is one way in which companies can keep a lead on their competitors. As such, this review provides insight into published work, and especially work done by government entities that deal with technology, such as NASA. 
Table 2: GAO Technology Readiness Level Desriptions ${ }^{3}$

\begin{tabular}{|c|c|}
\hline Technology Readiness Level & Description \\
\hline $\begin{array}{l}\text { 1. Basic principles observed and } \\
\text { reported. }\end{array}$ & $\begin{array}{l}\text { Lowest level of technology readiness. Scientific research begins to be translated into } \\
\text { applied research and development. Examples might include paper studies of a } \\
\text { technology's basic properties. }\end{array}$ \\
\hline $\begin{array}{l}\text { 2. Technology concept and/or } \\
\text { application formulated. }\end{array}$ & $\begin{array}{l}\text { Invention begins. Once basic principles are observed, practical applications can be } \\
\text { invented. The application is speculative and there is no proof or detailed analysis to } \\
\text { support the assumption. Examples are still limited to paper studies. }\end{array}$ \\
\hline $\begin{array}{l}\text { 3. Analytical and experimental } \\
\text { critical function and/or } \\
\text { characteristic proof of concept. }\end{array}$ & $\begin{array}{l}\text { Active research and development is initiated. This includes analytical studies and } \\
\text { laboratory studies to physically validate analytical predictions of separate elements of } \\
\text { the technology. Examples include components that are not yet integrated or } \\
\text { representative. }\end{array}$ \\
\hline $\begin{array}{l}\text { 4. Component and/or } \\
\text { breadboard validation in } \\
\text { laboratory environment. }\end{array}$ & $\begin{array}{l}\text { Basic technological components are integrated to establish that the pieces will work } \\
\text { together. This is relatively "low fidelity" compared to the eventual system. Examples } \\
\text { include integration of "ad hoc" hardware in a laboratory. }\end{array}$ \\
\hline $\begin{array}{l}\text { 5. Component and/or } \\
\text { breadboard validation in relevant } \\
\text { environment. }\end{array}$ & $\begin{array}{l}\text { Fidelity of breadboard technology increases significantly. The basic technological } \\
\text { components are integrated with reasonably realistic supporting elements so that the } \\
\text { technology can be tested in a simulated environment. Examples include "high fidelity" } \\
\text { laboratory integration of components. }\end{array}$ \\
\hline $\begin{array}{l}\text { 6. System/subsystem model or } \\
\text { prototype demonstration in a } \\
\text { relevant environment. }\end{array}$ & $\begin{array}{l}\text { Representative model or prototype system, which is well beyond the breadboard } \\
\text { tested for TRL 5, is tested in a relevant environment. Represents a major step up in a } \\
\text { technology's demonstrated readiness. Examples include testing a prototype in a high } \\
\text { fidelity laboratory environment or in simulated operational environment. }\end{array}$ \\
\hline $\begin{array}{l}\text { 7. System prototype } \\
\text { demonstration in an operational } \\
\text { environment. }\end{array}$ & $\begin{array}{l}\text { Prototype near or at planned operational system. Represents a major step up from } \\
\text { TRL } 6 \text {, requiring the demonstration of an actual system prototype in an operational } \\
\text { environment, such as in an aircraft, vehicle or space. Examples include testing the } \\
\text { prototype in a test bed aircraft. }\end{array}$ \\
\hline $\begin{array}{l}\text { 8. Actual system completed and } \\
\text { "flight qualified" through test and } \\
\text { demonstration. }\end{array}$ & $\begin{array}{l}\text { Technology has been proven to work in its final form and under expected conditions. } \\
\text { In almost all cases, this TRL represents the end of true system development. } \\
\text { Examples include developmental test and evaluation of the system in its intended } \\
\text { weapon system to determine if it meets design specifications. }\end{array}$ \\
\hline $\begin{array}{l}\text { 9. Actual system "flight proven" } \\
\text { through successful mission } \\
\text { operations. }\end{array}$ & $\begin{array}{l}\text { Actual application of the technology in its final form and under mission conditions, } \\
\text { such as those encountered in operational test and evaluation. In almost all cases, this } \\
\text { is the end of the last "bug fixing" aspects of true system development. Examples } \\
\text { include using the system under operational mission conditions. }\end{array}$ \\
\hline
\end{tabular}

The measurement of technology development is a useful ability. It enables specification of the progress of a technology from its initial concept to being an operational part of a system. Although some have come up with their own measures of technology progress $^{11}$ the generally accepted measure is the NASA-developed system of Technology Readiness Levels (TRL). ${ }^{25}$ The TRLs are an attempt to describe different stages in technology development through guidelines on the activities completed and knowledge available for each stage. The traditional NASA description of the levels is quite basic, though, and this basic description has been embellished upon by a number of organizations and individuals (eventually including $\mathrm{NASA}^{2}$ ) in order to make the process of classifying a technology's TRL simpler. ${ }^{26,27}$ One of the clearest descriptions is given by the United States General Accounting Office (GAO) which can be seen in Table 2.

One method that is used to aid management during the development of technology is the process of technology tracking. This process involves determining the technical capability of a technology as it evolves over time, as well as the evolving effect at the system level. Ward $^{24}$ defines the technology tracking process as having three phases, technology audit, metrics integration, and sensitivity analysis. The ASDL process, TMAT, expanded the Ward process to 5 phases, focusing on more detail in each phase. Part of technology tracking involves knowing what metrics to use to measure the performance of the technology. Martino $^{10}$ mentions that among other things a technology metric should be measurable, a true representation of the state of the art, and a metric for which data is readily available. Nuese ${ }^{28}$ adds to those statements that the technology metric must be a useful one. If it cannot be used to show the effect of the technology on the system level then it might be a waste of time to track that metric. Once suitable metrics are chosen they are tracked through gathering information on the estimated performance of those metrics at given time intervals. This information, usually provided by the individuals developing the technology, is translated into a form that can be used for analysis and then analysis is used to show the effect of the technology on the system level. 


\section{Technology Development:}

Although technology development is a process that is often proprietary, there is some general knowledge available as to how to conduct a technology development process. One researcher makes the point that it is important to focus on technical risk and not just the cost and time risk that is often addressed in general risk analysis projects. ${ }^{29}$ One of the GAO studies referenced earlier brought up the points that technology development must be transitioned carefully from the technologist to the program manager, and that the technology should be developed as far as possible before being included in a production program. That study also mentioned that it is best for a technology to be developed in the environment of a science and technology organization, instead of in a productoriented environment. ${ }^{3} \quad$ Sheasley $^{30}$ came up with a method for the management of technology development using the concept of cycle time management. There are indubitably many other methods available, but none are as extensively published as those undertaken by NASA.

As NASA is involved in a great deal of technology development (performed both internally and externally) a study of NASA methods in technology maturation or development is useful. The NASA Technology Plan ${ }^{2}$ gives guidelines for the use of technology in NASA endeavors. The technology plan does not give specific details on methods for technology development but does contribute in a few areas. The technology plan helps to develop the need for technology and states that some technologies will be developed in response to mission needs (mission pull) whereas some will be developed in areas where there is a projection of a future need (technology push). The plan also lays out needs in each of the NASA strategic enterprises: Space Sciences, Earth Science, Human Exploration and Development of Space, and Aero-Space Technology.

One study that focused on changes necessary in the many NASA technology development techniques was the "Framework for the Future" study performed by the NASA Chief Engineer and Integrated Action Team. ${ }^{31}$ This study concluded that current NASA methods for managing technology development, maturation, and infusion need to be improved. In order to adhere to the "Faster, Better, Cheaper" method, "better guidance and requirements are needed for program/project managers on how to identify, evaluate and assess, select, develop where necessary, and infuse technology within their missions." The study singled out the management process and among its recommendations listed the need for processes focused on assessing technology needs, tracking technology progress, and "guidance on conducting technology assessments at key program/project phases to evaluate feasibility; readiness; and lifecycle costs, risks, and benefits."
The Earth Science Enterprise (ESE), as a part of obtaining ISO9000 certification, detailed their technology development plan. ${ }^{32}$ Along with some broad enterprise-level strategy there are some specific guidelines given in the following phases of their development plan: conducting technology capabilities and needs assessments, identifying new technology projects and partnership opportunities, and prepare and update integrated technology development/investment plan. The last phase mentioned has some information about the development process for specific technologies but there is very little detail given. In a sense, there are broad guidelines on what needs to be done but no specific guidelines on how to accomplish those tasks.

One of the technology development efforts in the Office of Space Sciences (OSS) is the Next Generation Space Telescope (NGST). ${ }^{33}$ The NGST is described as being a large aperture infrared telescope. The Jet Propulsion Laboratory, one of the entities working on the project, detailed the technology development process for the project. The first step was demonstrating the need for the telescope and identifying what technological needs were evident due to the overall need. This was done by a number of outside contractor studies. The technology needs were cut down by an IPT (integrated planning team) to 10 key technology products that needed to be developed. These technologies ranged in TRL from a level of 2 to a level of 5-6, but the goal given was to develop all technologies to a level of 6 or higher to enable a smoother production process. Each technology was examined separately, and a series of development activities were listed. No guidelines were given as to how the activities were arrived at or how they would be managed as they developed. A schedule was found, however, which detailed the planned development effort in the form of a Gantt chart with specific milestones and activities listed for each of the technology products.

A final NASA-related insight into technology development is a study performed by SAIC for the NASA Systems Analysis Branch at the Langley Research Center. ${ }^{27}$ This study examined the time taken to develop technologies from "initial concept to marketable product." The study was performed by gathering data on a number of past development projects and examining the factors that affected the development time. It found that the time for development varied with technology type, the primary benefit or goal of the technology, and the need for additional technologies or NASA testing. Additional to these broad findings the study came up with some sample equations to attempt to express the trends in development time observed. 


\section{PROPOSED METHODOLOGY}

Taking into account the need demonstrated earlier, as well as the background information listed, the following process for technology development is suggested. Notice that this process is conceptual, but the steps listed will be validated through research and experimentation. The process assumes that the entity performing the study will have control over the process of technology development, either through developing the technology internally or through managing the project as it is performed by contract. The steps in this process are listed below, and a schematic is given in Figure 4.

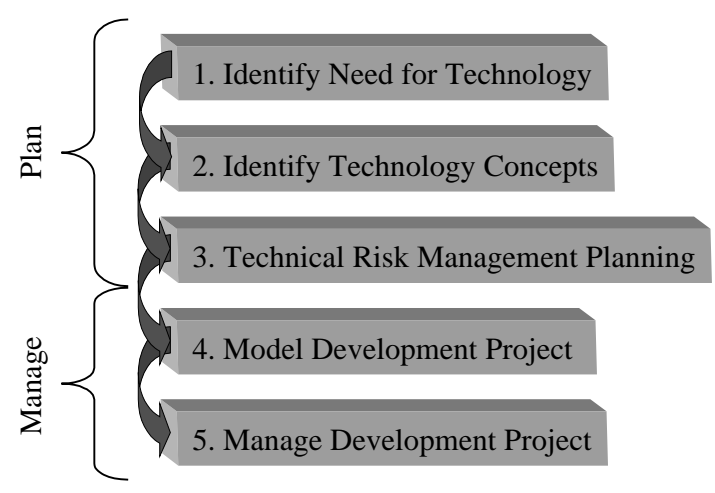

\section{Figure 4: Proposed Technology Development Process}

\section{Identify Need for Technology}

The first step in the development process is the identification of the need for technology. The TIES technique details one way to go about identifying the need. A more traditional method would be the use of expert opinion. It might be necessary to better define the need through breaking it down into more detail. In these cases techniques such as Pareto analysis and work breakdown structures could be used to identify the proper metrics at the level at which they must be defined.

\section{Identify Technology Concepts}

The next step in the process is to determine technology concepts that might be able to fill the identified need. These concepts should be analyzed as best as possible to determine that they match the need, and that any side effects do not create additional need for technology. If so, the additional need must also be identified. If there are a number of concepts, and it is not clear which should be developed, then they all should be analyzed using this process. This will allow an informed selection of the technology that is best suited (given early information) for the problem identified.

\section{Technical Risk Management Planning}

The next step is planning the method for managing the technical risks associated with the technologies. This should be done in the fashion of a traditional risk analysis process, through identifying, assessing, and controlling those risks.

Identify: The technical risks associated with utilizing the technologies must be identified. This can be done through a combination of the techniques listed earlier, likely through decomposition and expert opinion. The uncertainties identified must also be quantified in a probabilistic manner.

Assess: The risks must be assessed to determine if they are serious enough to require explicit management. This process will probably use simulation, though some of the other techniques identified in the background section might apply. The areas of uncertainty that show an appreciable effect on the overall goals can then be controlled.

Control: Risks identified in a technology are controlled through experimentation, analysis, and prototyping. For each of these risks, specific activities must be planned to reduce the identified uncertainty. These activities, while they will serve to reduce the technical risk, will introduce schedule and cost risk into the development project which will be addressed with the management portion of this process.

\section{Model the Development Project}

Once the activities that make up the technology maturation or development process have been specified the process must be modeled. Due to the inherent uncertainties involved with the unknown (in this case the technologies) these activities will have risk associated with their cost and time for completion. Modeling the project will assist in showing the overall cost and schedule risk due to uncertainty in the activities. This can be done using a number of methods, but the one that looks most promising is network analysis. This will model the structure of the process in a graphical manner and will provide information that will allow easier execution of the last phase of this process, the management of the technology development.

\section{Manage the Development Process}

The final phase of this process involves managing the development process that has been planned and modeled. Like any project, a project involving the development of technology will benefit from methodical management practices. Using the model created earlier it will be possible to control the cost and 
schedule risk and use the information created to perform tradeoffs. These tradeoffs can help to identify which technologies are the most appropriate ones to fully develop. In addition, as the development project progresses the model can be updated, providing new information that will allow better decisions to be made on how to manage the remainder of the project.

\section{CONCLUSION}

The process of technology development is critical to successful product development. The reason for this is that the purpose of technology development is the reduction of technical risk caused by the uncertainty inherent in new technology. Along with the technical risk, however, comes process risk, which can lead to cost and schedule slippage. There is a need for a process that can guide a technology development project in its planning and management, and focus on alleviation of all types of risk. The research that is described in this paper focused on identifying this need and determining that the problem described is real. The process shown here, although conceptual in nature, fills the need identified. Future work in this area will focus on filling in the details for the process, and demonstrating its effectiveness through a case study.

\section{REFERENCES}

1 Anderson, J.D., Introduction to Flight, Third Edition, New York, McGraw Hill, 1989.

NASA Technology Plan, 1998-2001, http://technologyplan.nasa.gov.

3 United States General Accounting Office, BEST PRACTICES: Better Management of Technology Development Can Improve Weapon System Outcomes, GAO/NSAID-99162, July 1999.

4 United States General Accounting Office, JOINT STRIKE FIGHTER ACQUISITION: Development Schedule Should Be Changed to Reduce Risks, GAO/NSIAD-00-74, May 2000.

5 Hartmann, G.C., Lakatos, A.I., "Assessing Technology Risk-A Case Study," Research \& Technology Management, March-April 1998, pp. 32-38.

6 Cooper, D.F., Chapman, C.B., Risk Analysis for Large Projects, Chichester, England, John Wiley and Sons Ltd., 1987.
7 Lockyer, K, Gordon, J., Project Management, and Project Network Techniques, Sixth Edition, London, Pitman Publishing, 1996.

8 Wilson, R., Shlyakhter, A., "Uncertainty and Variability in Risk Analysis" in Fundamentals of Risk Analysis and Risk Management, edited by Molak, V., CRC Press, Inc, Boca Raton, FL, 1997.

9 Kapur, K.C., "Quality Engineering and Tolerance Design" in Concurrent Engineering: Auromation, Tools, and Techniques, edited by Kusiak, A., John Wiley \& Sons, Inc., New York, 1993.

10 Martino, J.P., Technological Forecasting for Decision Making (Third Edition), McGrawHill, New York, 1993.

11 Michaels, J. V., Technical Risk Management, Prentice Hall, Upper Saddle River, NJ, 1996.

12 Vose, D., "Monte Carlo Risk Analysis Modeling" in Fundamentals of Risk Analysis and Risk Management, edited by Molak, V., CRC Press, Inc, Boca Raton, FL, 1997.

13 Brassard, M., The Memory Jogger Plus+, Goal/QPC, Methuen, MA, 1996.

14 Lee, S.M., Moeller, G.L., Digman, L.A., Network Analysis for Management Decisions, Boston, Kluwer Nijhoff Publishing, 1982.

15 Chapman, C.B., Ward, S.C., Project Risk Management, Processes, Techniques and Insights, Chichester, England, John Wiley and Sons Ltd., 1997.

16 Ruskin, A.M., Estes, W.E., What Every Engineer Should Know About Project Management, New York, Marcel Dekker, Inc., 1995.

17 Juran, J.M., "The Non-Pareto Principle; Mea Culpa", http://www.juran.com/research/articles/ SP7518.html.

18 Batson, R.G., "Cost Risk Analysis: A State-of-theArt Review," Estimator (refereed journal of the National Estimating Society), Spring 1989.

19 DeLaurentis, D.A., Mavris, D.N., Schrage, D.P., "System Synthesis in Preliminary Aircraft Design Using Statistical Methods," Presented at the 20th International Council of the Aeronautical Sciences (ICAS) Congress, Sorrento, Italy, September 8-13, 1996. 
Zink, P.S., Mavris, D.N., Flick, P.M., Love, M.H., "Impact of Active Aeroelastic Wing Technology on Wing Geometry using Response Surface Methodology," Presented at the CEAS/AIAA/ICASE/NASA Langley International Forum on Aeroelasticity and Structural Dynamics, Williamsburg, VA, June 22-25, 1999.

21 Kirby, M.R., “A Methodology for Technology Identification, Evaluation, and Selection in Conceptual and Preliminary Aircraft Design," Ph.D. Thesis, Georgia Institute of Technology, March 2001.

22 Mavris, D.N., Soban, D.S., Largent, M.C., "An Application of a Technology Impact Forecasting (TIF) Method to an Uninhabited Combat Aerial Vehicle," AIAA-99-01-5633.

23 Kirby, M.R., Mavris, D.N., Largent, M.C., "A Process for Tracking and Assessing Emerging Technology Development Programs for Resource Allocation," AIAA 2001-5280.

Ward, C.A., "Technology Tracking for the HighSpeed Research Program”, SAE-98-5549.

25 Commission on Engineering and Technical Systems, National Research Council, Maintaining U.S. Leadership in Aeronautics: Breakthrough Technologies to Meet Future Air and Space Transportation Needs and Goals, Washington D.C., National Academy Press, 1998.

Mankins, J.C., "Technology Readiness Levels," a white paper, April 6, 1995.

27 Peisen, D.J., et. al., Task Order 221, Case Studies: Time Required to Mature Aeronautic Technologies to Operational Readiness, NASA Draft Report, November, 1999.

28 Nuese, C.J., Building the Right Things Right, New York, Quality Resources, 1995.

29 Bodensteiner, W., Priest, J., "Managing the Technical Risks of the DevelopmentProduction Transition," Industrial Management, January-February 1988, pp. 1016.

30 Sheasley, W.D., "Leading the Technology development Process," Research \& Technology Management, May-June 1999, pp. 49-55.
NASA Chief Engineer and Integrated Action Team, "Enhancing Mission Success - A Framework for the Future", December 21, 2000.

32 Asrar, G.R., "Formulating ESE Technology Development", NASA document HOWI 7120Y011A, November 16, 1999.

33 Coulter, D.R., "Technology Development for the Next Generation Space Telescope", April 29, 1998 , http://www.ngst.nasa.gov/doclist/bytitle.html. 